\title{
"What are we doing to our babies' teeth?" Barriers to establishing oral health practices for Indigenous children in South Australia
}

\author{
Brianna Poirier ${ }^{1 *}$, Joanne Hedges ${ }^{1}$, Lisa Smithers ${ }^{2,3}$, Megan Moskos ${ }^{4}$ and Lisa Jamieson ${ }^{1}$
}

\begin{abstract}
Background: During the 1970s, optimal oral health was experienced more frequently amongst Indigenous children in Australia than their non-Indigenous counterparts. As a result of public health interventions targeting oral disease, oral health has improved for most children; however, Indigenous children today experience oral disease at alarmingly high rates. A history of colonisation, assimilation, racism and cultural annihilation has had profound impacts on oral health for Indigenous peoples; compounded by environmental dispossession and a shift from traditional diets to one of processed and nutrient-poor foods, often high in sugar.
\end{abstract}

Methods: This project aimed to identify factors related to the increased occurrence of caries in Indigenous children. Using purposive sampling from the larger project, this paper thematically analyses 327 motivational interviews to explore current barriers impeding parental efforts to establish oral health and nutrition practices for Indigenous children. Representation of socioeconomic positions of families were compared across themes, as based on maternal age, employment, residency and number of children in care.

Results: Findings resulted in a conceptual model of barriers that exist across knowledge, social, structural and parental factors. Major thematic results include: social consumption of processed foods, busy households, misleading nutrition marketing, sugar cravings and lack of oral health and nutrition knowledge.

Conclusion: A discussion of the findings results in the following recommendations increased oral health promotion efforts in non-metropolitan areas; utilisation of community experiences in creating strategies that encourage oral health and nutrition knowledge; and the extension of oral health initiatives and future research to include all family members.

Trial registration Australian New Zealand Clinical Trial Registry ACTRN12611000111976; registered 01/02/2011.

Keywords: Indigenous health, Oral health, Early childhood caries, Indigenous oral health, Nutrition knowledge, Oral health knowledge, Dental public health, Social determinants of health

*Correspondence: Brianna.poirier@adelaide.edu.au

${ }^{1}$ Australian Research Centre for Population Oral Health, Adelaide Dental

School, University of Adelaide, Adelaide 5000, Australia

Full list of author information is available at the end of the article

\section{Background}

According to the United Nations, Indigenous peoples include all those "having a historical continuity with preinvasion and pre-colonial societies that developed on their territories, who consider themselves distinct from other sectors of the societies now prevailing on those territories" [1]. Globally, Indigenous peoples experience a disproportionate burden of disease for many conditions,

(c) The Author(s) 2021. Open Access This article is licensed under a Creative Commons Attribution 4.0 International License, which permits use, sharing, adaptation, distribution and reproduction in any medium or format, as long as you give appropriate credit to the original author(s) and the source, provide a link to the Creative Commons licence, and indicate if changes were made. The images or other third party material in this article are included in the article's Creative Commons licence, unless indicated otherwise in a credit line to the material. If material is not included in the article's Creative Commons licence and your intended use is not permitted by statutory regulation or exceeds the permitted use, you will need to obtain permission directly from the copyright holder. To view a copy of this licence, visit http://creativecommons.org/licenses/by/4.0/. The Creative Commons Public Domain Dedication waiver (http://creativeco mmons.org/publicdomain/zero/1.0/) applies to the data made available in this article, unless otherwise stated in a credit line to the data. 
including obesity, non-insulin dependent diabetes, and dental caries [2]. A history of colonisation, governmentenforced assimilation, racism and cultural annihilation has had profound impacts on Indigenous health and is reflected in health inequities sustained by Indigenous communities today [3-5]. The forcible removal of communities from traditional lands, loss of traditional customs and languages, and subsequent environmental dispossession is an additional contributing factor to poor health because it has resulted in a transition from nutrient-dense traditional foods, to processed, nutrient-poor Western foods that are high in sugar $[6,7]$.

In Australia, Aboriginal and/or Torres Strait Islander (respectfully, subsequently referred to as 'Indigenous') communities flourished for 65,000 years prior to European invasion and colonisation [8]. Economic and social discrimination, processed diets, infectious disease, environmental dispossession and child removal are some of the ways in which processes of colonisation and government policies have intentionally disrupted Indigenous health in Australia [9]. Despite the Australian government's considerable resources allocated to addressing health inequities between Indigenous and non-Indigenous Australians, disparities continue to escalate [10, 11]. In Australia, $61 \%$ of Indigenous children experience decay in their primary teeth compared to $41 \%$ of nonIndigenous children and Indigenous children are more likely to have untreated decay in at least one primary tooth (44\%) than non-Indigenous children (26\%) [12].

The deleterious impacts of poor oral health in children are well documented. Pain, speech difficulties, lowered self-esteem and difficulty eating or sleeping are common consequences of ECC [13]; evidence suggests that more severe consequences impact children's growth, development, concentration, education attainment, quality of life, failure to thrive and can be life-threatening in some cases [14-18]. While ECC can have serious ramifications on health, the disease is entirely preventable with limited sugar consumption, proper oral hygiene, regular dental visits and sufficient fluoride exposure [18-20]. Childhood dental disease is the strongest indicator for adult dental disease $[16,21]$ and the greatest impact on childhood oral hygiene practices is caregiver influence, underscoring the importance of prevention efforts aimed at young children within the family setting [18, 22, 23]. Varying degrees of success have been experienced with population-level interventions for oral health, with water fluoridation being one of the most successful interventions in reducing ECC to date $[22,24]$. Despite fluoridation and educational programs for children and parents, barriers to oral health prevention persist for Indigenous communities as evidenced by the prevalence of ECC among Indigenous children [25].
In 2007, an Australian public service report detailed Indigenous health as a 'wicked' problem, difficult to solve and symptomatic of deeper concerns [26]. Present prevention strategies and policies do not consider the impact of issues, such as colonisation or structural barriers, that Indigenous peoples face in establishing good oral health $[9,27]$. Developing contextual understandings of the environments in which these health inequities persist is necessary when addressing such vast disparities [28]. Qualitative research offers an opportunity to further explore the experience and context of poor oral health among Indigenous peoples that has been extensively documented by quantitative findings. Therefore, the aim of this paper is to explore the complex context in which Indigenous Australians experience oral health, collate and interpret participants' experiences and develop an understanding of current barriers impeding parental efforts to establish oral health practices for their Indigenous children.

\section{Methods \\ Method}

Motivational Interviewing (MI) is a psychotherapy intervention that encourages participants to identify, explore and resolve obstacles to behaviour change [29]. Contrary to traditional health education approaches, MI is an empathetic behavioural support method rooted in the notion that knowledge alone is insufficient to elicit behaviour change, and that intrinsic motivation increases likelihood of behaviour change. MI creates an exploratory atmosphere for participants to articulate personal values, capacities and motives for behaviour change; emphasising an individual's personal motivation for change [30]. MI has previously been used to elicit oral health behaviour change for parents and their children [31, 32]. Importantly, MI parallels cultural values of Indigenous peoples, including oral traditions of storytelling and yarning [33], respects self-determination and is better able to yield a holistic and contextual understanding of a given issue $[34,35]$.

\section{Design}

This project was nested within a randomised control trial of an ECC intervention designed and conducted in partnership with Indigenous families and communities in South Australia. The protocol [36], primary quantitative results [37], and cohort profile have been published [38]. At baseline, the trial enrolled 448 women pregnant with an Indigenous child across South Australia. Participants were randomly allocated to intervention or control (delayed intervention) groups. There were four components to the intervention, (1) provision of dental care to mothers during pregnancy; (2) application of fluoride 
varnish to the teeth of children; (3) anticipatory guidance; and (4) MI. The findings presented in this paper are derived from the MI element of the trial. Motivational interviews were conducted with participants in the intervention group at baseline during pregnancy and when the child was aged 6-, 12-, and 18 months. The respective directives for each session were (1) encouraging dental care during pregnancy; (2) emphasising the importance of non-cariogenic foods and drinks for children; (3) emphasising the importance of fluoride in ECC prevention; (4) encouraging first dental appointment. Participants in the control group received MI at 24-, 30-, and 36 months, with the first session combining directives one and two.

\section{Participants and sampling}

For this qualitative analysis, we utilised purposive sampling of motivational interviews, based on the fidelity scores of trained staff who conducted the MI. Fidelity is defined as the extent to which an intervention is performed as intended [39]. Fidelity assessment of MI was completed to ensure sound methodological approach and scientific rigour in this trial [40]. The success of MI is contingent on interventionist competency and fidelity in eliciting participant statements of self-motivation and resistance to change [41]. Four trained staff conducted motivational interviews with varying compliance to the MI approach and different degrees of participant engagement. All included interviews for this analysis were completed by the single staff member that had the highest MI fidelity score. This decision was made because these interviews provided the richest data, constituted the majority of collected data and interviews were more comparable with one another than across interviews by other staff, which facilitated analysis. The staff with the highest fidelity score is a senior Indigenous researcher who utilised colloquial language and established trusting relationships with participants.

\section{Analysis}

It is important to acknowledge the assumptions one brings to qualitative research as they inescapably impact the interpretation of data and production of findings [42]. As a non-Indigenous researcher from Canada, the primary author took steps to familiarise herself with the data and the context in which it was collected prior to analysis. Local contextual and cultural understandings were enhanced through field work with the same communities and Indigenous health workers involved with this trial. Approximately one year was taken in reviewing, reading and listening to interviews. Understandings of data were extensively discussed with the senior Indigenous researcher who conducted the interviews $(\mathrm{JH})$ and the project's primary investigator (LJ) prior to initiating analysis. Braun and Clarke's [42-44] framework for reflexive thematic analysis guided the analytic process. Reflexive thematic analysis embraces the unique subjective skills a researcher brings to the project and enables organic identification of themes [42]. Inductive themes, grounded in the data, were coded line by line with NVivo 12 software (QSR International Pty Ltd. Version 12.6.1) and without a structured codebook to provide space for engaged interpretation of data. Once all transcripts had been coded, the data was re-visited, and similar codes were aggregated for iterative thematic development. Typically, reflexive thematic analysis does not utilise summary topics in conceptual models [42], however due to the quantity of codes, themes and transcripts analysed, as well as the multi-faceted context of Indigenous oral health, they are employed here to make sense of the ways in which barriers exist for participants.

The data from 357 interviews and 227 participants provided a unique opportunity to explore how socioeconomic positions might contribute to oral health experiences for carers. Subgroup comparisons were based on maternal age, residential location, number of children in care and employment status. These characteristics were chosen because the Australian Institute of Health and Welfare estimates that $34 \%$ of the health gap between Indigenous and non-Indigenous Australians is attributable to social determinants of health including income, employment and overcrowding [45] and in 2018, Indigenous mothers in Australia were most likely to be aged between 20 and 24 (31\%) [46]. The NVivo software attribute feature was utilised to assign characteristics to participant transcripts and thematic codes. Matrices were utilised to compare the relationships between participants and themes, demographics and participants, and demographics and themes. Subsequent analysis determined how many participants within each demographic subgroup discussed a given theme (Fig. 1).

\section{Results}

Respondents discussed a number of factors that create barriers for participants to establish oral health practices. These included knowledge factors, parental factors, structural factors and social factors (Fig. 2). The findings below are presented in order of highest to lowest frequency that respondents mentioned a particular theme: knowledge factors (3232), parental factors (1632), structural factors (902), and social factors (623). Findings represent discussions from 357 interviews with 227 parents or carers of Indigenous children aged 6-36 months from across South Australia (50.7\% of baseline sample). Participant characteristics varied across the included demographic measures of employment, number of children 


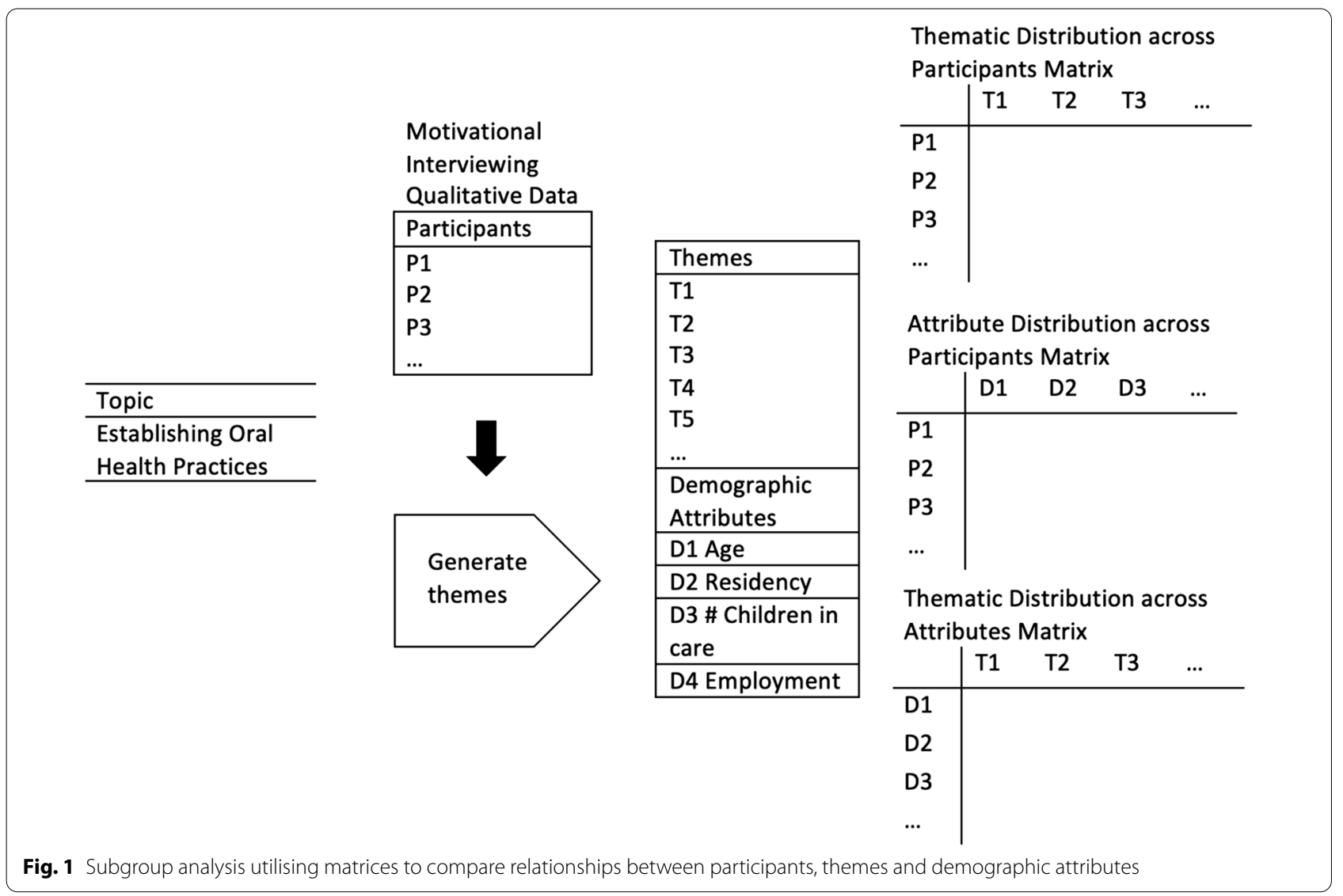

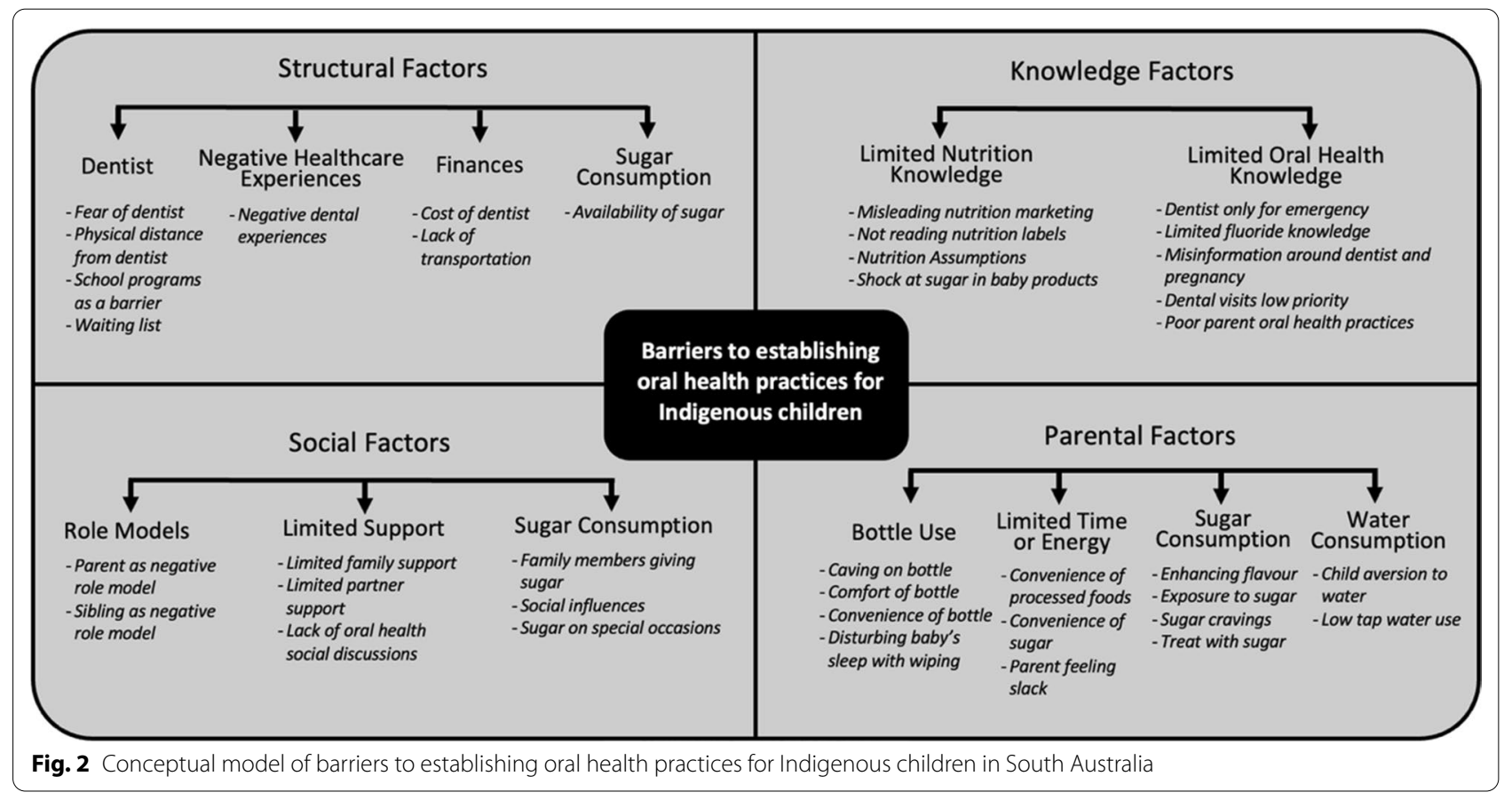


in care, residential location and maternal age (Table 1). The majority of the sample were older than 25 (66.1\%), had 1-3 children in their care (67.6\%), were unemployed $(69.6 \%)$ and resided in metropolitan areas (56.8\%).

\section{Knowledge factors}

Knowledge was discussed by participants as critical to ensuring strong oral health practices for their children, with many individuals desiring more education or knowledge in specific areas. Limited nutrition knowledge was a prominent theme across all interviews and all participants. Generally, there were a lot of misconceptions about what is healthy for children, "He does have chocolate but I only give him the Kinder Surprise chocolate because it's got more of the milk in it." Further discussion with parents revealed that a lot of this confusion was confounded due to misleading nutrition marketing and resulting nutrition assumptions:

[Baby food is] advertised [as being] good for your baby and healthy for your baby and a lot of them claim ... it's pure fruit, no added sugar... That's a bit sad because a lot of Mums especially when you're shopping, you're busy, you go well this is supposed to be healthy for my baby, it's on special, I'm going to chuck it in my trolley. And not realising that it could be doing more harm than good.

Many parents cited front of pack marketing as a key information source in terms of nutrition decisions made for their children. When parents were asked to order baby food from highest to lowest according to sugar content, almost all parents who did not read the nutrition

Table 1 Participant characteristics

\begin{tabular}{lc}
\hline & $\begin{array}{l}\text { Participants (N=227) } \\
\text { N (\%) }\end{array}$ \\
\hline Maternal age & $77(33.9 \%)$ \\
$16-24$ & $150(66.1 \%)$ \\
$25+$ & \\
Children in care & \\
$1-3$ & $142(67.6 \%)$ \\
$4+$ & $68(32.4 \%)$ \\
Employment ${ }^{2}$ & \\
Full time & $20(9.5 \%)$ \\
Part time & $44(20.9 \%)$ \\
Unemployed & $147(69.6 \%)$ \\
Residential location & $129(56.8 \%)$ \\
Metropolitan & $98(43.2 \%)$ \\
Non-metropolitan & \\
${ }^{1} \mathrm{~N}=210$ (data not available for all included participants) \\
${ }^{2} \mathrm{~N}=211$ (data not available for all included participant)
\end{tabular}

label ranked items based on nutrient claims included on product packaging, specifically 'no added sugar.' Many carers were taken aback when they discovered that the baby food with the 'no added sugar' claim was the highest in sugar: "[That]'s disgusting. They shouldn't be able to make things like that, they should have a big sign on the front, [with] 'high sugar content', like they do with smoking."

Limited oral health knowledge concerning topics such as when children should have their first dental visit, when to start using a toothbrush and how much toothpaste is safe for children was common: "Can you brush his teeth too much? Is there a limit to how many times we can brush their teeth during the day?" Many parents were confused or did not have the correct oral health knowledge:

(Interviewer): How would you go about getting the bugs and sugar off his teeth after he's had a bottle and he's sleeping? (Mum): I really don't know. I would just assume that the saliva will wash it away when he's sleeping.

Fluoride knowledge was highly varied, with some parents identifying fluoride as cancer-causing, a whitening agent or a caffeine source. The initial interview for the intervention group occurred during pregnancy and many mothers had misinformation around dental visits during pregnancy, worrying that it could put their baby in harm's way. Once this was clarified and mothers understood that dental visits were safe, many were willing to go, even if they had not been in years.

Poor parent oral health practices, as a result of limited oral health knowledge, were discussed as a barrier to establishing child oral health. Some parents shared that they cannot expect their children to brush their teeth or reduce sugar consumption when their own actions contrast these expectations. Some parents identified dental visits as low priority because "it's something I've never done" or "I just don't feel like it." Other parents discussed oral health as a lower priority amongst competing obligations. This notion provides insight to the practice of only using dental care for emergencies:
I think we'll probably just [go to the dentist] when he starts to get holes in his teeth or if his teeth are hurt- ing or something fell out or if he's fallen down and [lost] his tooth and probably then I would take him to the dentist. That's what I did with all the other ones. When they start to get holes or they need some- thing done to their teeth that's when I take them to the dentist.

Shock at amount of sugar in baby food, misleading nutrition marketing and nutrition assumptions were 
the knowledge factors discussed by the highest number of participants; these themes were mentioned most frequently by metropolitan families, families with one to three children and unemployed parents (Additional file 1).

\section{Parental factors}

Parental factors relate to barriers associated with selfidentified habits, feelings, or justifications contributing to debilitating oral health habits. The majority of parents identified sugar consumption as detrimental to their child's oral health, and then utilised concepts including flavour enhancement, sugar cravings, and treating with sugar as justification for exposing their child to sugar. Parents commonly described adding sugar to cereal or water for children to "make it taste better." Sugar cravings were discussed in terms of parent addiction as well as children; children would often cry or throw a tantrum until parents succumbed to the child's demands. Some parents justified giving sugar because of their cravings: "You can't expect them to give up because I'm addicted to Coke, you know, so, just give it." Using sugar to spoil children was common, even for children who were not yet on solids: "I only give her honey on the dummy every now and then because I like just to give her treats but it's not all the time."

Many parents were actively trying to wean children from night-time bottles, more so due to worries about choking or misalignment of teeth, rather than dental decay prevention. Numerous parents talked about caving on bottle removal attempts, often because of the comfort associated with the bottle:

It seems to be her comfort thing for her bed. Like she's got a blanket but... Well she's got a room full of toys too but she seems to like just to lay down and drink a bottle and just play with my hair. And that's how she goes to sleep. So I don't really want to take it away from her because that's her comfort thing.

Convenience of bottles was another barrier to reducing bottle reliance: "It's bad, but there's nothing I can do about it unless I don't want to get any sleep." A lot of parents were hesitant to wipe their baby's teeth after feeding because they worried they may disturb the baby's sleep. Limited time or energy was another barrier; some parents mentioned they had been feeling slack and brushing teeth, making food at home or other preventive behaviours were not their primary concern.

He's very full-on, so [I] just feed him and then do my washing and then after the washing he's probably in something, doing something and it's just too fullon to be able to [read nutrition labels]. If it had on the front of the packaging how many tablespoons of sugar, I'd probably think a second about getting him certain things, but it doesn't. People don't have time to read that. The mums that I know... they just go for what's easy.

The convenience of processed foods and sugar were discussed as a factor of limited time and the easiest option, especially when at sporting or social events and when travelling: "I have tried a few of these [baby foods] when we're travelling because they made it quite handy to keep in the esky and just whip it out to give her something." For parents who identified low water consumption in their children, the two primary barriers were child aversion to water and low household tap water use. Some households used rainwater as their primary source of water usually due to access and taste preference.

Limited time or energy, exposure to sugar and comfort of bottle were the parental barriers discussed by the highest number of participants; these three themes were cited most frequently by families in non-metropolitan areas, families with one to three children, unemployed parents, and older parents. (Additional file 1).

\section{Structural factors}

Physical distance from dental providers as well as long wait times were structural barriers for families, with mothers waiting between eighteen months and eight years for a public dentist appointment. Many participants discussed a fear of dental visits as a barrier to booking and attending appointments. Several parents were under the impression that school dental visits, common in primary schools across Australia, were sufficient in place of regular dental check-ups. This assumption prevented parents from taking their children for dental visits and waiting until the child was at least 5 years old and eligible for the school programs. While this program intends to facilitate strong oral health, it created confusion for participants around when to access dental services for their children:

\section{In kindy they take [kids] to the dentist and stuff. I just thought when they go to kindy they usually send home a note saying there's a dentist coming, is it alright if they can see you? The dentist comes and if the dentist says there's any problems that's when I'll take them to the dentist. I never thought about taking her before... I thought all kids just went to the dentist when they went to school.}

Financial limitations were discussed in terms of the cost of dental care and transportation to appointments. When participants were informed about funding schemes or offered transportation to dental visits, many that had 
previously been unable to go were happy to attend. Parents cited previous negative healthcare experiences as a barrier to pursuing preventive healthcare and these experiences directly influenced parental perceived negative reaction of children at their first dental visit. Specific stories of negative dental experiences were shared, and a few parents discussed experiences of racism:

I've noticed with when you go to doctors and all that ... like dentists, especially being a black woman they don't talk to you, they talk to the secretary, or whatever it is, about you. And then you've got to remind them hello, I'm sitting in the room you know, you've got to kind of put your foot down... I think that they think that I don't know what ... they're talking about, you know... I want to be treated with the proper respect that everybody else gets because you can see it when you walk into the doctors they look at you like oh, another black person.

The structural component of sugar consumption related to the sheer availability of sugar. The industrialisation of food production has rapidly transformed the food landscape for communities, especially for those in rural and remote areas, where reliance on processed foods have increased due to limited access to fresh foods. Parents expressed being overwhelmed at the availability of sugar and exhaustion at navigating which foods are healthy for their families: "It's terrible. It's just in everything, sugar's in everything. And like I said, you know, some things you think there's not much sugar in them, [but] it's you know right at the top [of the ingredient list]."

Parent perceived negative reaction of child at dental visits, availability of sugar and financial limitations were the structural barriers cited by the greatest number of families, lack of transportation was only mentioned as a barrier by unemployed parents and experiences of racism when accessing health services was only mentioned by employed parents (Additional file 1).

\section{Social factors}

Social factors were concerned with community and social environments in which oral health exists. Limited family support was a barrier for parents who needed help with transportation or babysitting for dental visits. Some parents touched on the difficulty of maintaining oral health when extended family assist with childcare but do not respect their routines. Parents with limited partner support described the burden of responsibility for all aspects of their children's lives, which often resulted in a lowered priority for oral health. Limited partner support was also discussed as poor communication or respect between parents regarding oral health routines. Lack of oral health social discussions at parent support groups or among friends was commonly discussed.

Household role models, including parent and sibling negative influence, were identified as barriers to establishing oral health practices for children. Parents identified themselves as a negative influence with regard to sugar consumption, saying that they couldn't justify limiting their children's sugar when they were addicted. Many parents described letting older children have sugar, which frequently resulted in the taunting of younger child or sneaking them lollies. Sugar consumption was heavily impacted by social settings and special occasions. Family members giving sugar was the most common theme within social factors; parents expressed frustration at family members disobeying their wishes and overriding their efforts to restrict sugar consumption. Parents suggested that giving sugar was a way for relatives to show their love, but many families dismissed the potential impacts on the child's health. Some parents even talked about staying at home more often to control sugar consumption: "When we go to my mum and dad's it's like because my other nephew is there and they've got [sugar] ... and baby [goes], what's that? So that's why we try and stay home."

Family members giving sugar was the social barrier cited by the highest number of participants, across all subgroup characteristics. Younger parents and those in non-metropolitan regions frequently discussed the barrier of negative sibling and parental role model. Families in metropolitan regions most frequently discussed sugar on special occasions and a lack of social oral health discussions (Additional file 1).

\section{Discussion}

Indigenous oral health inequities in Australia are well documented [4, 15, 16, 18, 22, 47-49]. However, few projects have highlighted Indigenous voices and documented personal perspectives, providing context for the experience of Indigenous oral health in Australia [27, 50-53]. This project is unique in that it employed an open-ended approach to discussion, through the use of MI, and provided space for participants to ask questions and direct the conversation [30]. The results emphasise the multi-faceted circumstances in which Indigenous oral health exists for new mothers and their children with identification of barriers across parental, structural, social and knowledge factors. Many findings from this project reinforce previously identified barriers to oral health for Indigenous communities including: availability of sugar $[18,51]$, inaccessibility of oral health care $[15$, $27,54]$, racism $[27,52,55]$, poor parent oral health practices [53, 56, 57], lack of accessible transport [27, 52, 57], limited time and energy [50], competing health priorities 
$[27,50,51]$, waiting times [27, 52], financial limitations $[27,50-52,55,58]$, school dental programs $[50,52]$, limited oral health knowledge $[27,53,54]$ and limited nutrition knowledge $[51,52]$.

Findings of self-identified poor parent oral health practices, fear of dentist, waiting lists, physical distance from dentist, financial limitations, negative health care experiences and limited oral health knowledge work together to tell an important story that parents shared during this project. The impact of these factors results in low dental attendance and lack of emphasis on prevention, which is alarming because regular dental visits increase the probability of diagnosing, managing and limiting oral disease [59]. Similarly, Butten et al. [51] found a lack of prevention efforts amongst Indigenous mothers in Queensland due to the complex interplay of financial, personal and structural factors. The availability of school dental programs shaped parents' perceptions of child oral health needs in this project, which limited prevention efforts as parents did not identify a need to take children for dental visits earlier; for many five-year-old children, it is too late for preventive actions and restorations are needed. Indigenous mothers in Queensland utilised school dental programs for older children, but many did not take their pre-school children for dental visits [50]. Regular dental attendance and prevention efforts underscore healthy trajectories, behaviours and improved quality of life for children [59-61]. Indigenous children have the highest rates of dental surgery under general anaesthesia and the occurrence is increasing; in Australia, Indigenous children have twice the rate of hospital-based dental surgery under a general anaesthetic compared to non-Indigenous children [47]. The high cost, risks and logistical implications of dental surgery, as well as recurrence of disease provides precedence for the prioritisation of prevention over treatment of ECC [13]. Additionally, prevention is the most cost-effective mechanism to addressing ECC, with research suggesting that fifty dollars is saved on restoration procedures for every dollar spent on prevention [62]. Findings from this project are representative of carers with children 36 months and younger; Indigenous mothers from Queensland have described the increased difficulties experienced when trying to maintain oral health routines as children age, which further stresses the importance of establishing good oral health habits at a young age [50].

Limited parental oral health knowledge impacts a child's oral health due to the close relationship between caregiver oral health and child oral health [18]. Both parent tooth brushing habits and attitudes or knowledge towards oral health have been associated with ECC development in children [63, 64]. Limited oral health knowledge directly impacts child health as poor maternal oral health is related to adverse birth outcomes [65]. This trial encouraged pregnant mothers to attend dental appointments and to take children around 18 months of age. Limited oral health knowledge persisted among participants who attended dental appointments, highlighting the importance of sustained awareness efforts and behaviour change programs for oral health prevention. Dental services are not covered for adults under Medicare, the public funding system, in Australia; while a public dental service exists, they are stipulated by eligibility criteria and often have long wait times and private options require large out-of-pocket fees [66]. Our findings highlighted common misinformation around dental visits during pregnancy. Current evidence-based guidelines recommend that women seek dental care early in pregnancy and identify the importance of midwives in facilitating this, however access for many pregnant mothers remains low [52, 67]. Previous research suggests that lack of referral knowledge and competing health matters are barriers to prioritising oral health for midwives in Australia [68] and limited oral health training exists for Aboriginal Health Workers [27]. Mandating oral health education for all health professionals has been suggested as a way to increase accessibility of oral health [50]. The importance of culturally appropriate, ongoing and informal dissemination of oral health information has been noted elsewhere $[52,54]$ and the lack of social oral health discussions identified by participants in this project reinforces the need for community-level education and health promotion.

Knowledge factors also extended to nutrition knowledge in our project. Misleading nutrition marketing, nutrition assumptions, shock at amount of sugar in baby food and not reading nutrition labels were all findings related to limited nutrition knowledge. Limited knowledge in conjunction with other factors such as limited time or energy, convenience of processed foods, financial limitations and availability of sugar, resulted in a constrained ability of parents to make healthy food choices. For the majority of parents in our project, nutrient claims were the primary source of nutrition information and largely influenced food decisions. Many parents were upset once they realised the nutrition assumptions that they had made due to misleading marketing. Similarly, Indigenous mothers in Queensland identified that they had 'done the wrong thing' by giving children milk or juice because they believed it was healthy. The concept of a 'health halo' has been reported in previous research and occurs when nutrient or health claims lead to consumer interpretations of a product being healthier than it actually is [69]. In our project, one parent suggested using warning labels for high sugar content, similar to cigarette packaging; a First Nations participant in a Canadian 
study suggested the same idea: “...[T]he same scope of thinking [like] they do with cigarettes: they should put [warning labels] on the candy bars" [54]. The relationship between these factors underscores the importance of nutrition education for parents and consideration of the impact that nutrient claims on baby foods have on nutrition assumptions and food choices. Stronger regulation for claims using nutrient profiling has previously been called for in Australia due to consumer tendency to infer health benefits as highlighted in our findings [70].

In this study, sugar consumption included was related to availability, social influences, limited parental nutrition knowledge, flavour enhancement and convenience of sugary foods and drinks. It is well understood that dietary factors, specifically sugar consumption, increase the availability of fermentable carbohydrates required for acid formation and ECC development, while simultaneously increasing host susceptibility due to the influence of prenatal and infant nutrition on enamel development $[56,71]$. The misconception that baby teeth are less important than permanent dentition was cited as rationale for exposing children to sugar, this perception has previously been identified as a barrier to preventive care in young Indigenous children [50]. Many parents in our project talked about the availability of sugar as a barrier to decision making because "it's everywhere." Similarly, Indigenous mothers from Queensland identified lower sugar exposure during their own childhood, when compared to their children, because processed foods were not as common [50]. The transition from traditional diets to Western diets, due to processes of colonisation and a loss of traditional foods, has been explored and identified as a contributing factor to a variety of health inequities experienced by Indigenous peoples globally [7]. Sugar consumption is influenced by many factors within the home, school and wider community environments [18, 72]. Even when parents are attempting to limit consumption, they cannot control what happens in schools or with other family members. Beyond an increase in knowledge, healthy food choices need to be possible within a given environment and when education efforts do not consider environmental influence, they are ineffective at initiating behaviour change [73].

The subgroup comparison provided insight into how different socioeconomic positions influence barriers to establishing oral health practices for Indigenous children. Lower socioeconomic status is directly related to oral health disparities in Australia [68] and, indeed, globally [74]. One of the largest trends was that families living in non-metropolitan areas were more likely to identify barriers across all subgroups than those living in metropoli$\tan$ areas. This finding highlights the need for holistic, targeted dental public health efforts in rural and remote communities across South Australia. Parent employment status, children in care and maternal age impacted frequency of barrier identification in various ways. The subgroup comparison highlights barriers for families of different demographics and has the potential to inform future policy, research and interventions for specific subsets of the population.

\section{Strengths and limitations}

This paper adds to the limited qualitative research on Indigenous oral health in Australia and highlights Indigenous voices that illustrate the challenges carers face in optimising oral health for their children within Westernised environments. The structural barriers identified by parents are part of a system that has historically excluded Indigenous voices despite their direct impact on Indigenous health [75]. A strength of this project is the use of $\mathrm{MI}$ as the conversational methodology respected through Indigenous traditions of yarning, and provided the space and time for participants to engage in conversations [30]. The variation in prominence of themes is representative of participant's experiences due to the structure of MI where the interviewer is positioned as a knowledgeable person accessible for participants to engage with on topics, rather than prioritising topics and questions with a structured guide. Additionally, this project is unique in that socioeconomic positions were compared to identify how barriers exist for families in different situations. A limitation of the study is that baseline measures for age and employment used for subgroup comparisons reflect maternal characteristics rather than the entire household. Additionally, the majority of interviews were conducted with mothers at baseline occurred during pregnancy, however future projects would be more impactful by prioritising paternal participation and engaging the whole family, as aligned with cultural understandings of holistic health.

\section{Conclusion}

Despite the barriers shared by participants and discussed here, parents understood the importance of oral health and desired the best possible outcome for their children's teeth. Policymakers, researchers and public health professionals are urged to consider the barriers experienced firsthand by Indigenous peoples and prioritise Indigenous partnerships when addressing oral health disparities. Our recommendations from these findings include an increased focus on oral health promotion efforts in non-metropolitan areas; the utilisation of community experiences and needs in creating useful strategies that encourage oral health and nutrition knowledge; and the extension of oral health initiatives and future research to include all family members. 


\section{Abbreviations}

ECC: Early Childhood Caries; FT: Full-time; Metro: Metropolitan; Nonmetro: Non-Metropolitan; MI: Motivational Interviewing; PT: Part-time; UE: Unemployed.

\section{Supplementary Information}

The online version contains supplementary material available at https://doi. org/10.1186/s12903-021-01791-x.

Additional file 1. Participant comparison by demographic characteristics within knowledge, parental, structural, and social factors.

\section{Acknowledgements}

We would like to extend our gratitude to all of the children and families involved in this trial as well as the research team, in particular the Aboriginal Health Services and other organisations without whose support this project would not be possible. We would like to thank the MI coach and fidelity assessor for training our team and ensuring sound methodological application. Finally, we would like to pay our respects to those who have passed away during this project and are remembered for their contributions to the study.

\section{Authors' contributions}

$\mathrm{BP}, J \mathrm{H}, \mathrm{LGS}, \mathrm{MM}$ and LMJ contributed to the conceptualisation of this analysis. $\mathrm{BP}$ interpreted and analysed the data. JH collected data; $\mathrm{JH}$ and MM aided in data analysis. Writing and original draft preparation were done by BP. Writing review and significant editing were performed by JH, LGS, MM and LMJ. All authors read and approved the final manuscript.

\section{Funding}

The authors disclosed receipt of the following financial support for the research, authorship, and publication of this article: National Health and Medical Research Council of Australia (NHMRC, Project Grants 627350 and 1153662) and Channel 7 Children's Research Foundation grant (10547012). The views expressed in this publication are those of the authors and do not reflect the views of the NHMRC or Channel 7.

\section{Availability of data and materials}

The datasets analysed during the current study are not publicly available due to confidentiality concerns but are available from the corresponding author on reasonable request.

\section{Declarations}

\section{Ethics approval and consent to participate}

This study was conducted in accordance with the World Medical Association Declaration of Helsinki 2013. The project received ethical approval from the Aboriginal Health Council of South Australia (04-09-362) and the University of Adelaide Human Research Ethics Committee (H-057-2010). Written informed consent was obtained from all participants.

\section{Consent for publication}

Not applicable.

\section{Competing interests}

The authors declare that they have no competing interests.

\section{Author details}

${ }^{1}$ Australian Research Centre for Population Oral Health, Adelaide Dental School, University of Adelaide, Adelaide 5000, Australia. ${ }^{2}$ School of Public Health and the Robinson Research Institute, University of Adelaide, Adelaide 5000, Australia. ${ }^{3}$ The School of Health and Society, University of Wollongong, Wollongong 2522, Australia. ${ }^{4}$ Future of Employment and Skills Research Centre, Faculty of the Professions, University of Adelaide, Adelaide 5000, Australia.
Received: 20 April 2021 Accepted: 23 August 2021

Published online: 06 September 2021

\section{References}

1. Declaration on the rights of Indigenous Peoples. Geneva, Switzerland: United Nations; 2008

2. Paradies Y. Colonisation, racism and indigenous health. J Popul Res (Canberra, ACT). 2016;33(1):83-96.

3. Durie M. An Indigenous model of health promotion. Health Promot J Austr. 2004;15(3):181-5

4. Jamieson L, Haag D, Schuch H, Kapellas K, Arantes R, Thomson WM. Indigenous oral health inequalities at an international level: a commentary. Int J Environ Res Public Health. 2020;17(11):3958.

5. King MP, Smith AMD, Gracey MP. Indigenous health part 2: the underlying causes of the health gap. The Lancet (British edition). 2009:374(9683):76-85.

6. Richmond CAM, Ross NA. The determinants of First Nation and Inuit health: a critical population health approach. Health Place. 2009;15(2):403-11.

7. Kuhnlein HV, Receveur O. Dietary change and traditional food systems of indigenous peoples. Annu Rev Nutr. 1996;16(1):417-42.

8. Lourandos H. Continent of hunter-gatherers: new perspectives in Australian prehistory. Cambridge: Cambridge University Press; 1997.

9. Steffens M, Jamieson L, Kapellas K. Historical factors, discrimination and oral health among aboriginal Australians. J Health Care Poor Underserved. 2016;27(1):30-45.

10. Healthy Mouths, Healthy Lives; Australia's National Oral Health Plan 2015-2024. Canberra, Australia: COAG Health Council; 2015.

11. Aboriginal and Torres Strait Islander health performance framework 2012: detailed analyses. Canberra, Australia: Australian Institute of Health and Welfare; 2013

12. Australia's children. Canberra: Australian Institute of Health and Welfare; 2020.

13. Baghdadi ZD. Effects of dental rehabilitation under general anesthesia on children's oral health-related quality of life using proxy short versions of OHRQoL instruments. Sci World. 2013;2014:308439-45.

14. Alkarimi HA, Watt RG, Pikhart H, Sheiham A, Tsakos G. Dental caries and growth in school-age children. Pediatrics (Evanston). 2014;133(3):e616-23.

15. Schroth RJDMDM, Harrison RLDMDMM, Moffatt MEKMDMF. Oral Health of Indigenous Children and the Influence of Early Childhood Caries on Childhood Health and Well-being. Pediatric Clin N Am. 2009;56(6):1481-99.

16. de Silva AM, Martin-Kerry J, Geale A, Cole D. Flying blind: trying to find solutions to Indigenous oral health. Aust Health Rev. 2016;40(5):570-83.

17. Kramer PF, Feldens CA, Helena Ferreira S, Bervian J, Rodrigues PH, Peres MA. Exploring the impact of oral diseases and disorders on quality of life of preschool children. Commun Dent Oral Epidemiol. 2013;41(4):327-35.

18. Chi DL. Reducing Alaska Native paediatric oral health disparities: a systematic review of oral health interventions and a case study on multilevel strategies to reduce sugar-sweetened beverage intake. Int J Circumpolar Health. 2013;72(1):21066.

19. Batliner T, Fehringer KA, Tiwari T, Henderson WG, Wilson A, Brega AG, et al. Motivational interviewing with American Indian mothers to prevent early childhood caries: study design and methodology of a randomized control trial. Trials. 2014;15(1):125.

20. Moynihan P. Sugars and dental caries: evidence for setting a recommended threshold for intake. Adv Nutr (Bethesda, MD). 2016;7(1):149-56.

21. Roberts-Thomson KF, Spencer AJ, Jamieson LM. Oral health of Aboriginal and Torres Strait Islander Australians. Med J Aust. 2008;188(10):592-3.

22. Ha DH, Do LG, Roberts-Thomson K, Jamieson L. Risk indicators for untreated dental decay among Indigenous Australian children. Commun Dent Oral Epidemiol. 2019;47(4):316-23.

23. Bruerd B, Jones C. Preventing baby bottle tooth decay: eight-year results. Public Health Rep. 1996;111(1):63-5

24. Whelton HP, Spencer AJ, Do LG, Rugg-Gunn AJ. Fluoride revolution and dental caries: evolution of policies for global use. J Dent Res. 2019:98(8):837-46. 
25. Nash DA, Nagel RJ. Confronting Oral Health Disparities Among American Indian/Alaska Native Children: The Pediatric Oral Health Therapist. Am J Public Health. 2005;95(8):1325-9.

26. Tackling wicked problems: a public policy perspective. Canberra, Australia: Australian Public Service Commission; 2007.

27. Durey A, McAullay D, Gibson B, Slack-Smith L. Aboriginal Health Worker perceptions of oral health: a qualitative study in Perth, Western Australia. Int J Equity Health. 2016;15(1):4.

28. Horst WJR, Melvin MW. Dilemmas in a general theory of planning. Policy Sci. 1973;4(2):155-69.

29. Miller WR, Rollnick S. Ten things that motivational interviewing is not. Behav Cogn Psychother. 2009;37(2):129-40.

30. Magill M, Gaume J, Apodaca TR, Walthers J, Mastroleo NR, Borsari B, et al. The technical hypothesis of motivational interviewing: a meta-analysis of Ml's key causal model. J Consult Clin Psychol. 2014;82(6):973-83.

31. Harrison R, Benton T, Everson-Stewart S, Weinstein P. Effect of motivational interviewing on rates of early childhood caries: a randomized trial. Pediatr Dent. 2007;29(1):16-22.

32. Weinstein $P$, Harrison R, Benton T. Motivating mothers to prevent caries: confirming the beneficial effect of counseling. J Am Dent Assoc. 2006;137(6):789-93.

33. Walker M, Fredericks B, Mills K, Anderson D. "Yarning" as a method for community-based health research with indigenous women: the indigenous women's wellness research program. Health Care Women Int. 2014;35(10):1216-26.

34. Kovach M. Conversation method in indigenous research. First Peoples Child Fam Rev. 2010;5(1):40-8.

35. Smith LT. Decolonizing methodologies: research and indigenous peoples. London: Zed Books; 1999.

36. Merrick J, Chong A, Parker E, Roberts-Thomson K, Misan G, Spencer $J$, et al. Reducing disease burden and health inequalities arising from chronic disease among Indigenous children: an early childhood caries intervention. BMC Public Health. 2012;12(1):323.

37. Jamieson L, Smithers L, Hedges J, Parker E, Mills H, Kapellas K, et al. Dental disease outcomes following a 2-year oral health promotion program for Australian aboriginal children and their families: a 2-arm parallel, singleblind. Random Control EClin Med. 2018;1:43-50.

38. Jamieson LM, Hedges J, Ju X, Kapellas K, Leane C, Haag DG, et al. Cohort profile: South Australian Aboriginal Birth Cohort (SAABC)-a prospective longitudinal birth cohort. BMJ Open. 2021;11(2):e043559.

39. Santacroce SJ, Maccarelli LM, Grey M. Intervention fidelity. Nurs Res (New York). 2004:53(1):63-6.

40. Jamieson L, Bradshaw J, Lawrence H, Broughton J, Venner K. Fidelity of motivational interviewing in an early childhood caries intervention involving indigenous Australian mothers. J Health Care Poor Underserved. 2016;27(1):125-38.

41. Gaume JMA, Gmel GPD, Faouzi MPD, Daeppen J-BMD. Counselor skill influences outcomes of brief motivational interventions. J Subst Abuse Treat. 2009:37(2):151-9.

42. Braun V, Clarke V. One size fits all? What counts as quality practice in (reflexive) thematic analysis? Qual Res Psychol. 2020:1-25.

43. Braun V, Clarke V. Using thematic analysis in psychology. Qual Res Psychol. 2006:3(2):77-101.

44. Braun V, Clarke V. Reflecting on reflexive thematic analysis. Qual Res Sport Exerc Health. 2019;11(4):589-97.

45. Aboriginal and Torres Strait Islander Health Performance Framework 2017 Report. Canberra: Australian Institute of Health and Welfare; 2017.

46. Australia's mothers and babies 2018: in brief. Canberra: Australian Institute of Health and Welfare; 2020. Contract No.: 36.

47. Jamieson LM, Roberts-Thomson KF. Dental general anaesthetic trends among Australian children. BMC Oral Health. 2006;6(1):16

48. Jamieson LMPE, Armfield JM. Indigenous child oral health at a regional and state level. J Paediatr Child Health. 2007;43(3):117-21.

49. Schuch HS, Haag DG, Kapellas K, Arantes R, Peres MA, Thomson WM, et al The magnitude of Indigenous and non-Indigenous oral health inequalities in Brazil, New Zealand and Australia. Commun Dent Oral Epidemiol. 2017:45(5):434-41.

50. Butten K, Johnson NW, Hall KK, Toombs M, King N, O'Grady K-AF. Impact of oral health on Australian urban Aboriginal and Torres Strait Islander families: a qualitative study. Int J Equity Health. 2019;18(1):34.
51. Butten K, Johnson NW, Hall KK, Toombs M, King N, O'Grady K-AF. Yarning about oral health: perceptions of urban Australian Aboriginal and Torres Strait Islander women. BMC Oral Health. 2020;20(1):35.

52. Durey A, McAullay D, Gibson B, Slack-Smith LM. Oral health in young Australian aboriginal children: qualitative research on parents' perspectives. JDR Clin Transl Res. 2017;2(1):38-47

53. Jamieson LM, Parker EJ, Richards L. Using qualitative methodology to inform an Indigenous-owned oral health promotion initiative in Australia. Health Promot Int. 2008:23(1):52-9.

54. Kyoon-Achan G, Schroth RJ, Sanguins J, Campbell R, Demaré D, Sturym $M$, et al. Early childhood oral health promotion for First Nations and Métis communities and caregivers in Manitoba. Health Promot Chronic Dis Prev Can. 2021;41(1):14-24.

55. Ben JJL, Parker EJ, Roberts-Thomson KF, Lawrence HP, Broughton J. Paradies $Y$ Experience of racism and tooth brushing among pregnant Aboriginal Australians: exploring psychosocial mediators. Community Dent Health. 2014;31(3):145-52.

56. Irvine JD, Holve S, Krol D, Schroth R. Early childhood caries in Indigenous communities: a joint statement with the American Academy of Pediatrics. Paediatr Child Health. 2011;16(6):351-7.

57. Kong AC, Ramjan L, Sousa MS, Gwynne K, Goulding J, Jones N, et al. The oral health of Indigenous pregnant women: a mixed-methods systematic review. Women Birth J Austr Coll Midwives. 2020;33(4):311-22.

58. Broughton JR, Person M, Maipi JTH, Cooper-Te KR, Smith-Wilkinson A, Tiakiwai $S$, et al. Ukaipō niho: the place of nurturing for oral health. NZ Dent J. 2014;110(1):18-23.

59. Crocombe LA, Broadbent JM, Thomson WM, Brennan DS, Poulton R. Impact of dental visiting trajectory patterns on clinical oral health and oral health-related quality of life. J Public Health Dent. 2012;72(1):36-44.

60. Harrison RL, Veronneau J, Leroux B. Effectiveness of maternal counselling in reducing caries in Cree children. J Dent Res. 2012;91(11):1032-7.

61. Patricia AB, Kimberly EL, William GH, Angela GB, David OQ, Judith A. Validation of a pediatric oral health-related quality of life scale in Navajo children. Qual Life Res. 2015;24(1):231-9.

62. Tooth decay in Ontario's children: An ounce of prevention-a pound of care. Ontario Dental Association; 2008.

63. Gibson S, Williams S. Dental caries in pre-school children: associations with social class, toothbrushing habit and consumption of sugars and sugar-containing foods. Further analysis of data from the National Diet and Nutrition Survey of children aged $1.5-4.5$ years. Caries Res. 1999:33(2):101-13.

64. Leake J, Jozzy S, Uswak G. Severe dental caries, impacts and determinants among children 2-6 years of age in Inuvik Region, Northwest Territories, Canada. Journal (Canadian Dental Association). 2008;74(6):519.

65. Boggess KA, Edelstein BL. Oral health in women during preconception and pregnancy: implications for birth outcomes and infant oral health. Matern Child Health J. 2006:10(S1):169-74

66. Oral health and dental care in Australia. Australian Institute of Health and Welfare; 2019

67. George A, Johnson M, Blinkhorn A, Ajwani S, Ellis S, Bhole S. Views of pregnant women in South Western Sydney towards dental care and an oral-health program initiated by midwives. Health Promot J Austr. 2013;24(3):178-84

68. Lim M, Riggs E, Shankumar R, Marwaha P, Kilpatrick N. Midwives' and women's views on accessing dental care during pregnancy: an Australian qualitative study. Aust Dent J. 2018;63(3):320-8.

69. Hawley KL, Roberto CA, Bragg MA, Liu PJ, Schwartz MB, Brownell KD. The science on front-of-package food labels. Public Health Nutr. 2013;16(3):430-9.

70. Wellard-Cole L, Li R, Tse C, Watson WL, Hughes C. Changes in nutrition content and health claims post-implementation of regulation in Australia. Public Health Nutr. 2020:23(12):1-2227.

71. Lawrence HP, Binguis D, Douglas J, McKeown L, Switzer B, Figueiredo R, et al. A 2-year community-randomized controlled trial of fluoride varnish to prevent early childhood caries in Aboriginal children. Commun Dent Oral Epidemiol. 2008;36(6):503-16.

72. Sheiham A, Watt RG. The common risk factor approach: a rational basis for promoting oral health: common risk factor approach. Commun Dent Oral Epidemiol. 2000;28(6):399-406. 
73. Martin D, McNally M, Castleden H, Worden-Driscoll I, Clarke M, Wall D, et al. Linking inuit knowledge and public health for improved child and youth oral health in NunatuKavut. JDR Clin Transl Res. 2018;3(3):256-63.

74. Peres MA, Macpherson LMD, Weyant RJ, Daly B, Venturelli R, Mathur MR, et al. Oral diseases: a global public health challenge. The Lancet (British edition). 2019;394(10194):249-60.

75. Castleden HMD, Campbell D. Embedded in to marginalized out of place: Indigenous peoples' experience of health in Canada. In: Giesbrecht MCV, editor. Place, health, and diversity: learning from the Canadian experience. New York: Routledge; 2016.

\section{Publisher's Note}

Springer Nature remains neutral with regard to jurisdictional claims in published maps and institutional affiliations.
Ready to submit your research? Choose BMC and benefit from:

- fast, convenient online submission

- thorough peer review by experienced researchers in your field

- rapid publication on acceptance

- support for research data, including large and complex data types

- gold Open Access which fosters wider collaboration and increased citations

- maximum visibility for your research: over $100 \mathrm{M}$ website views per year

At BMC, research is always in progress.

Learn more biomedcentral.com/submissions 